\title{
Voltammetric determination of dopamine and norepinphrine on a glassy carbon electrode modified with poly (L-aspartic acid)
}

\author{
ZHANGYU YU ${ }^{\mathrm{a}, \mathrm{b}, \mathrm{c}, *}$, XIAOCHUN LI ${ }^{\mathrm{a}, \mathrm{b}}$, XUELIANG WANG ${ }^{\mathrm{a}}, \mathrm{XINYING} \mathrm{MA}^{\mathrm{a}}, \mathrm{XIA} \mathrm{LI}^{\mathrm{a}}$ and \\ KEWEI CAO ${ }^{\mathrm{a}, \mathrm{b}}$ \\ a Department of Chemistry and Chemical Engineering, Heze University, Heze, 274015, \\ People's Republic of China \\ ${ }^{b}$ Department of Chemistry and Chemical Engineering, Qufu Normal University, Qufu, 273165, \\ People's Republic of China \\ ${ }^{\mathrm{c}}$ College of Chemistry and Chemical Engineering, Shandong University, Jinan, 250010, \\ People's Republic of China \\ e-mail: yuzywxl@163.com
}

MS received 7 May 2011; revised 26 July 2011; accepted 8 August 2011

\begin{abstract}
A convenient and useful method for the voltammetric determination of dopamine (DA) and norepinphrine (NE) based on poly(L-aspartic acid) modified glassy carbon electrode (GCE) is reported in this paper. The modified electrode exhibits excellent electro-catalytic activities for the oxidation-reduction of DA and NE, as well as eliminating the interference of ascorbic acid (AA) and uric acid (UA). Factors influencing the detection processes are optimized and the kinetic parameters are calculated. Under the optimal conditions, the anodic peak currents of DA and NE are linear with their concentration and the detection limits $(\mathrm{S} / \mathrm{N}=3)$ are $1.0 \times$ $10^{-9} \mathrm{~mol} \mathrm{~L}^{-1}$ for DA and $4.31 \times 10^{-9} \mathrm{~mol} \mathrm{~L}^{-1}$ for NE, respectively. The practical application of this method is demonstrated by determining the concentration of NE and DA in injection which is commercially available with satisfactory results. Compared with other electrochemical methods, this method is simple, highly selective and sensitive.
\end{abstract}

Keywords. L-aspartic acid; modified electrode; dopamine; norepinephrine.

\section{Introduction}

Dopamine (DA) and norepinephrine (NE) are important neurotransmitters with general catecholamine structure. DA is an important intermediate species in tyrosine conversion to NE in vivo. NE is secreted and released by the adrenal glands and the noradrenergic neurons during synaptic transmission. They play important roles in the function of human metabolism, cardiovascular, central nervous, renal, and hormonal systems. The abnormal concentration level of them is a symptom for monitoring and diagnosing diseases. Therefore, there is an intense research focus to develop rapid and sensitive methods for determination of DA and NE, and many methods have been employed, such as chromatographic methods, ${ }^{1-4}$ spectrophotometry, ${ }^{5,6}$ fluorometry ${ }^{7,8}$ and various electrochemical methods. ${ }^{9-25}$

Electrochemical methods provide a simple, costeffective and quick way of analysing biologically and environmentally important molecules. However, the

*For correspondence major problem for voltammetric detection of DA or $\mathrm{NE}$ in real samples is the interference of the concomitant compounds, such as ascorbic acid (AA) and uric acids (UA), which generally results in overlapped voltammetric response due to their very similar oxidation peak potentials. ${ }^{9,10}$ Nowadays, chemicallymodified electrode surface has been proved to be a successful strategy to circumvent this problem, and various materials and techniques have been used. ${ }^{9,10}$ Among those modified electrodes, amino acids modified electrodes have many merits such as good biocompatibility, stability, easiness of the preparation and easily available materials ${ }^{26-28}$ apart from some limitations which are common with all modified electrodes like coverage dependence and durability.

In this work, L-aspartic acid is electro-polymerized on a glassy carbon electrode (GCE) with cyclic voltammetry, and the electrochemical behaviours of DA and $\mathrm{NE}$ are studied on the poly(L-aspartic acid) modified GCE. The results show that the modified electrode has excellent properties for determination of DA and $\mathrm{NE}$, and eliminating the interference of ascorbic acid (AA) and uric acid (UA). Compared with other similar 
methods, this method has wide dynamic linear range and low detection limits.

\section{Experimental}

\subsection{Materials and apparatus}

Dopamine (DA) and Norepinephrine (NE) are purchased from National Institute for the Control of Pharmaceutical and Biological Products (Beijing, China). Dopamine hydrochloride injection $\left(10 \mathrm{mg} \mathrm{mL}^{-1}\right)$ and norepinephrine bitartrate injection $\left(2 \mathrm{mg} \mathrm{mL}^{-1}\right)$ are purchased from Wuhan Grand Pharmaceutical Group Co., Ltd (Wuhan, China) and Shanghai Harvest Pharmaceutical Co., Ltd (Shanghai, China), respectively. L-aspartic acid (L-Asp) is purchased from Tianjin Guangfu Fine Chemical Research Institute (Tianjin, China). The injection of NE is produced by Chongqing Dikang Yangtze River Pharmaceutical Co., Ltd. (Chongqing, China). Ascorbic acid (AA) and uric acid (UA) are purchased from Tianjin Kemiou Chemical reagent Co., Ltd. (Tianjin, China) and Sinopharm Chemical Reagent Co., Ltd. (Shanghai, China), respectively. Phosphate-buffer saline (PBS, $0.1 \mathrm{~mol} \mathrm{~L}^{-1}$ $\mathrm{KH}_{2} \mathrm{PO}_{4}+0.1 \mathrm{~mol} \mathrm{~L}^{-1} \mathrm{~K}_{2} \mathrm{HPO}_{4}+0.1 \mathrm{~mol} \mathrm{~L}^{-1} \mathrm{KCl}$, $\mathrm{pH}$ 5.0) is used as supporting electrolyte. The solution of L-Asp is prepared with PBS ( $\mathrm{pH}$ 5.0) which has been deaerated by bubbling highly pure nitrogen. All chemicals were of analytical grade and used without further purification. Water used in experiments is redistilled water.

All electrochemical experiments were performed on a CHI 660 C electrochemical workstation (Shanghai $\mathrm{CH}$ Instruments, China) with a three-electrode arrangement consisting of a glassy carbon electrode (GCE) $(\Phi=3.0 \mathrm{~mm})$ or film-coated GCE working electrode, a saturated calomel reference electrode (SCE) and a platinum wire auxiliary electrode. The $\mathrm{pH}$ values of all solutions are measured by a model pHS-25 digital acidometer (Shanghai Leici Factory, China).

\subsection{Preparation of the modified electrode}

Prior to modification, the GCE is pre-treated as follows: first, the GCE is treated to a mirror-like by polishing with wet $4^{\#}$ and $6^{\#}$ metallographic sandpapers and $0.05 \mu \mathrm{m} \alpha-\mathrm{Al}_{2} \mathrm{O}_{3}$ slurry on a polishing cloth, then the electrode is sonicated for $5 \mathrm{~min}$ in nitric acid, ethanol and redistilled water in sequence, finally, the electrodes are treated by cyclic scanning to stable in the potential range of $-0.50-1.80 \mathrm{~V}$ in $0.5 \mathrm{~mol} \mathrm{~L}^{-1} \mathrm{H}_{2} \mathrm{SO}_{4}$ solution. After each step, rinsed with water and ethanol, and dried at room temperature. Using this pre-treated electrode as working electrode, the cyclic voltammetry is performed in $\mathrm{pH}$ 5.0 PBS solution containing $2.0 \times 10^{-3} \mathrm{~mol} \mathrm{~L}^{-1}$ L-Asp in the potential range of $0.80-2.40 \mathrm{~V}$ at the scan rate of $100 \mathrm{mV} \mathrm{s}^{-1}$ for eight cycles, and then the LAsp is polymerized on the electrode. Taking out the electrode and rinsing with ethanol, water and $0.1 \mathrm{~mol}$ $\mathrm{L}^{-1} \mathrm{PBS}$ ( $\mathrm{pH}$ 5.0), to remove any physi-absorbed, unreacted materials from the electrode surface, the L-Asp modified electrode is ready. The prepared electrode is denoted as PL-Asp/GCE. It is stored in $0.1 \mathrm{~mol} \mathrm{~L}^{-1}$ PBS ( $\mathrm{pH}$ 5.0) solution at room temperature for use.

\subsection{Electrochemical detection}

The electrochemical determination of DA is performed in PBS ( $\mathrm{pH}$ 5.0) with cyclic voltammetry in the range of $0.0-0.6 \mathrm{~V}$ at the scan rate of $100 \mathrm{mV} \mathrm{s}^{-1}$. All solutions were deaerated by bubbling highly pure nitrogen prior to measurements and a nitrogen atmosphere was maintained during the whole course of determination. The electrochemical determination of NE was carried out in PBS (pH 4.0). Other conditions are the same as DA.

\section{Results and discussion}

\subsection{Electrochemical polymerization of L-Asp on GCE}

The repetitive cyclic voltammograms of $2.0 \times 10^{-3} \mathrm{~mol}$ $\mathrm{L}^{-1} \mathrm{~L}$-aspartic acid are shown in figure 1. L-Asp has one cathodic peak (Peak 1) and two anodic peaks (Peak $2,3)$. The redox reactions of L-Asp are irreversible at

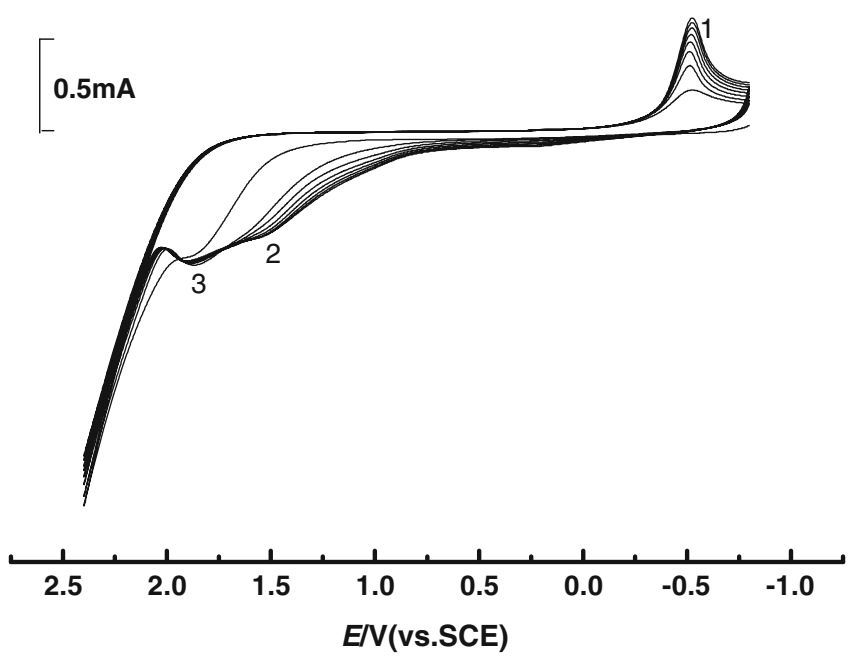

Figure 1. Cyclic voltammograms of $2.0 \times 10^{-3} \mathrm{~mol} \mathrm{~L}^{-1}$ L-aspartic acid at the GCE. Scan rate: $100 \mathrm{mV} \mathrm{s}^{-1}$; Support electrolytes: $0.1 \mathrm{~mol} \mathrm{~L}^{-1}$ PBS ( $\mathrm{pH} 5.0$ ). 


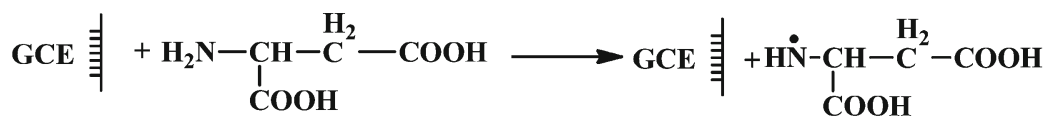

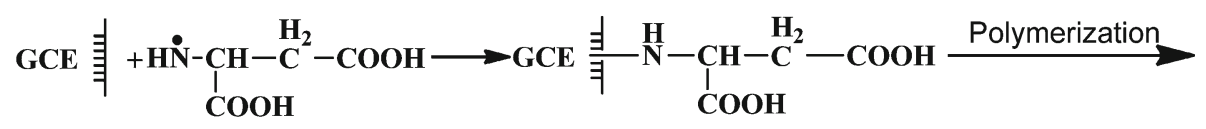<smiles>CC(C)(NC(CC(=O)O)C(=O)O)NC(C)(C)C(=O)C(C)(C)NC(C(=O)O)C(=O)C(C)(C)NC(CC(=O)O)C(=O)O</smiles>

Figure 2. The electro-polymerization of L-aspartic acid on the GCE.

the GCE. The cathodic peak currents (Peak 1) increase with the scan cycle numbers up to 8, then remain constant. The electrode is taken out and washed with redistilled water to remove the physically adsorbed material. After dried in air, a gray colour poly L-Asp film can be seen at the electrode surface obviously, indicating that an electroconductive polymer film is formed on the electrode surface.

The influence of the potential range on the L-Asp membrane formation is also studied. The potential range from -0.8 to $+2.4 \mathrm{~V}$ is chosen in this work. If the positive potential is lower than $+1.8 \mathrm{~V}$, the polymer film cannot be obtained. This could be ascribed to the lack of the radical cation at the oxidative potential lower than $+1.8 \mathrm{~V}$. If the positive potential is beyond $+2.4 \mathrm{~V}$, it would lead to over-oxidation of L-Asp and the deterioration of the polymer film. The L-Asp monomer is oxidized first at a higher positive potential to form $\alpha$-amino free radical, ${ }^{26-28}$ which could be linked on an electrode surface and then formed poly(L-Asp) films (figure 2).

\subsection{Electrochemical response of DA on the $P L-A s p / G C E$}

The electrochemical response of $1.05 \times 10^{-5} \mathrm{~mol} \mathrm{~L}^{-1}$ DA on the PL-Asp/GCE was studied by cyclic voltammetry and the results are shown in figure 3. DA has a couple of definite redox peaks on the PL-Asp/GCE in PBS ( $\mathrm{pH}$ 5.0) (Curve c) and no oxidation-reduction peak currents on the bare GCE. The cathodic peak potential $\left(E_{\mathrm{pc}}\right)$ and the anodic peak potential $\left(E_{\mathrm{pa}}\right)$ are at $0.306 \mathrm{~V}$ and $0.226 \mathrm{~V}$, respectively. The formal potential $\left(E^{0}\right)$ is $0.266 \mathrm{~V}$ and the $i_{\mathrm{pa}} / i_{\mathrm{pc}}$ is approximate to 1 . Therefore, the electrochemical reactions of DA at the modified electrode are a quasi-reversible reaction process. However, no obvious peak currents on the PLAsp/GCE in PBS (pH 5.0) are found. The results show that the membrane of PL-Asp could catalyse the redox reaction of DA and facilitate its electron transfer. The good properties of the membrane are ascribed to its three-dimensional structure and the rich carboxyl groups. The carboxyl groups could combine together with the hydroxyl groups in DA to form hydrogen bond. The formation of the hydrogen bond could weaken the bond energy of hydroxyl in DA and enrich DA on the electrode surface. Therefore, the rate of electron transfer is accelerated and the current is increased.

On the PL-Asp/GCE, NE had almost the same response as DA (Curve d). NE also has a couple of oxidation-reduction peak currents on the PL-Asp/GCE and no oxidation-reduction peak currents on the bare GCE. The formal potential $\left(E^{0}\right)$ of NE is $0.275 \mathrm{~V}$ on the PL-Asp/GCE. The anodic peak currents of DA and NE

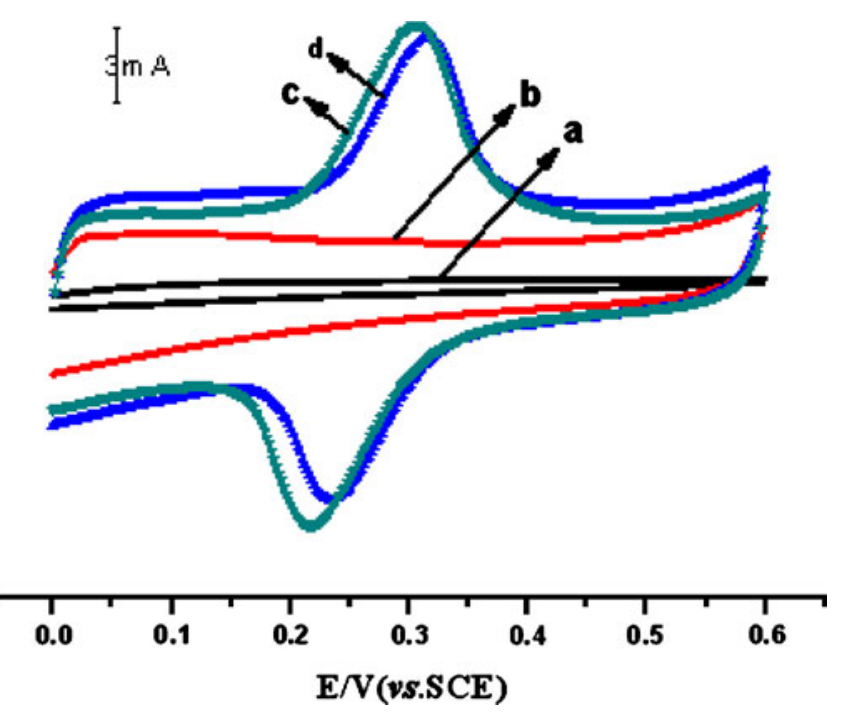

Figure 3. The cyclic voltammograms of $1.05 \times 10^{-5} \mathrm{~mol}$ $\mathrm{L}^{-1} \mathrm{DA}$ on the bare electrode (a) and PL-Asp/GCE (c), the PL-Asp/GCE in pH 5.0 of PBS (b). The cyclic voltammograms of $1.58 \times 10^{-5} \mathrm{~mol} \mathrm{~L}^{-1} \mathrm{NE}$ on the PL-Asp/GCE (d). Scan rate: $100 \mathrm{mV} \mathrm{s}^{-1}$. 

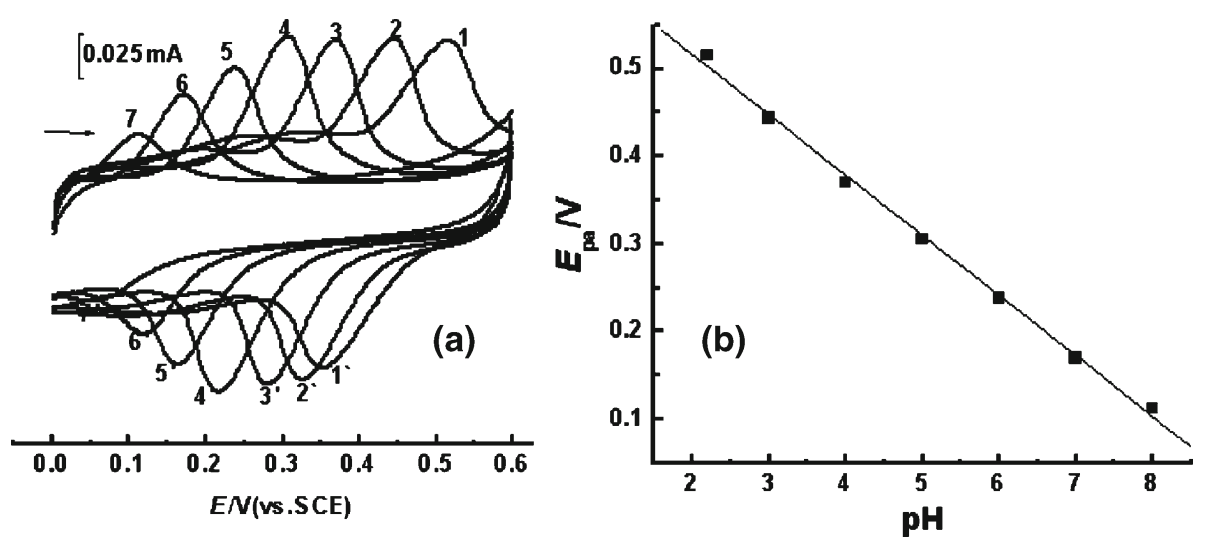

Figure 4. Cyclic voltammograms of $1.05 \times 10^{-5} \mathrm{~mol} \mathrm{~L}^{-1} \mathrm{DA}$ at different $\mathrm{pH}$ values (a) and the shift of the oxidation potential value with the value of $\mathrm{pH}(\mathbf{b})$. The $\mathrm{pH}$ of curve $1-7$ was $2.2,3.0,4.0,5.0,6.0,7.0,8.0$, respectively. Scan rate: $100 \mathrm{mV} \mathrm{s}^{-1}$.

can be used as the signals for quantitative determination of them.

Using DA as an indicator, the properties of the PL-Asp membrane is studied by electrochemical impedance spectroscopy (EIS) on the electrochemical working station. EIS is an effective method for probing the features of surface modified electrode. In the Nyquist plot of impedance spectra, the semicircle portion at higher frequencies correspond to the electron transfer limited process and the electron transfer resistance (Ret) at the electrode surface is equal to this semicircle diameter, which can be used to describe the interface properties of the electrode. ${ }^{29}$ The results show that the Ret values which are obtained on the bare electrode and PL-Asp/GCE are $6823 \Omega$ and $132 \Omega$, respectively, indicating that the electron transfer rate of DA at the PL-Asp/GCE is faster than that at the bare electrode.

\subsection{Optimum of analytical condition}

The influence of the $\mathrm{pH}$ value on the redox of DA is studied and the cyclic voltammograms of $1.05 \times$ $10^{-5} \mathrm{~mol} \mathrm{~L}^{-1} \mathrm{DA}$ at different $\mathrm{pH}$ values are demonstrated in figure $4 \mathrm{a}$. The oxidation potential value shifted with the $\mathrm{pH}$ value is demonstrated in figure $4 \mathrm{~b}$. It could be seen that both the cathodic and anodic peaks potential of DA negatively shifted with the increase of $\mathrm{pH}$ values, which show that the $\mathrm{H}^{+}$took part in the electrode reaction of DA. The peak current reaches the biggest value at $\mathrm{pH}$ 5.0. So the optimum $\mathrm{pH} 5.0$ is used in this work. The influence of $\mathrm{pH}$ on the oxidation of $\mathrm{NE}$ is also studied in the same ways, and the optimum pH 5.0 is selected.

The influence of potential scan rate, $v$, on the oxidation-reduction of $1.05 \times 10^{-5} \mathrm{~mol} \mathrm{~L}^{-1} \mathrm{DA}$ is studied and the results are shown in figure 5. The results show that both cathodic and anodic peak currents increase with the scanning rate, and the peakto-peak separation $\left(\Delta E_{p}\right)$ becomes bigger and bigger simultaneously, which indicate that the reversibility of the reactions on the PL-Asp/GCE is getting worse. In this experiment, the scan rate of $100 \mathrm{mV} \mathrm{s}^{-1}$ was selected for the DA determinations.

The studies on the relationship between $\lg i_{\mathrm{pa}}$ and $\lg v$ at different concentrations of DA (table $\mathrm{S} 1$ in the supporting information) show that the slopes of $\lg i_{\mathrm{pa}} v s . \lg v$ are decreased with the concentration of DA. The slopes are approximate to 1 and 0.5 when the DA concentrations are $1.05 \times 10^{-7} \mathrm{~mol} \mathrm{~L}^{-1}$ and $1.05 \times 10^{-3} \mathrm{~mol} \mathrm{~L}^{-1}$, respectively. The results indicate that the reaction on the

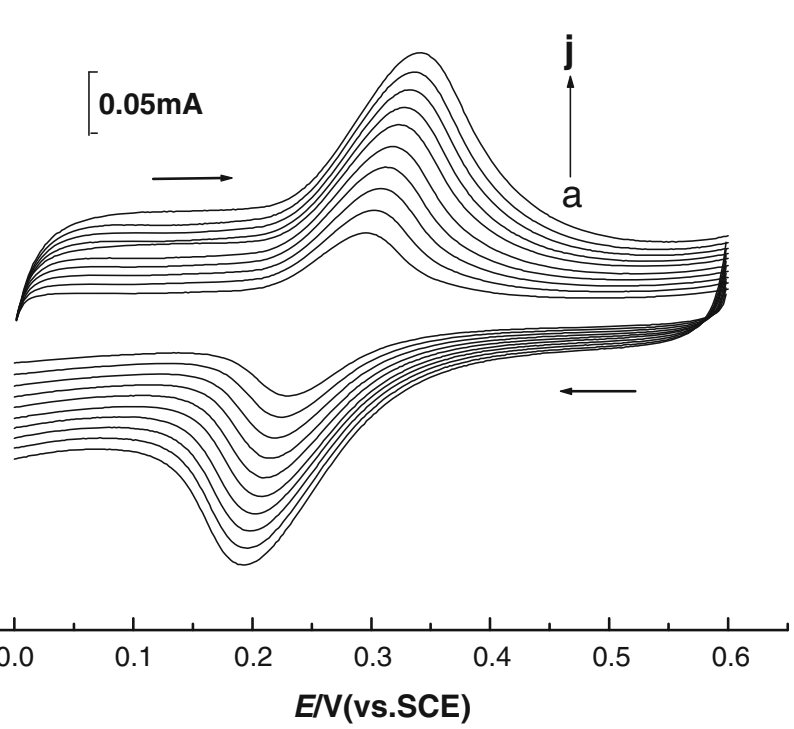

Figure 5. Cyclic voltammograms of $1.05 \times 10^{-5} \mathrm{~mol} \mathrm{~L}^{-1}$ DA on the PL-Asp/GCE at different scanning rate: a.40; b.60; c. 80 ; d.100; e.120; f.140; g.160; h.180; i. 200; j. $220 \mathrm{mV} \mathrm{s}^{-1}$. 
modified electrode is controlled by different modes for different concentration of DA. Further study indicates that the electrochemical behaviours of $\mathrm{NE}$ are almost same as that of DA.

\subsection{Calculation of the electrochemical parameters related to the electrode reaction of DA and NE}

When the concentration of DA is $1.05 \times 10^{-5} \mathrm{~mol} \mathrm{~L}^{-1}$, the slopes of $\lg i_{\mathrm{pa}} v s . \lg v$ is 0.7257 , so the reaction on the electrode is an adsorption-controlled quasireversible reaction. The relationship between $E_{\mathrm{pa}}$ and $\ln v$ in the cyclic voltammetry could be expressed in Eq. (1) by Laviron. ${ }^{30}$

$$
\begin{aligned}
E_{p}= & E^{0}+[R T /(\alpha n F)] \ln \left[\left(R T k_{s}\right) /(\alpha n F)\right] \\
& -[R T /(\alpha n F)] \ln v
\end{aligned}
$$

where $k_{s}$ is the standard rate constant of the surface reaction; $n, F, \alpha, R$ and $T$ have their usual significance. According to the Eq. (1), $k_{s}=1.13 \mathrm{~s}^{-1}$ and $a n=0.78$ are calculated from the slope and intercept of $E_{\mathrm{pa}}(\mathrm{V})=$ $0.0284 \ln v+0.178(\mathrm{r}=0.9976)$. In most systems $\alpha$ turns out to lie between 0.3 and 0.7 , and it can usually be approximated by 0.5 in the absence of actual measurements. ${ }^{31}$ So the number of electron $(n)$ involved in the reaction is calculated to be $1.56 \approx 2$. In the same ways, for $\mathrm{NE}$, the $k_{s}$ is $31.96 \mathrm{~s}^{-1}$ and $n$ is calculated to be $1.81 \approx 2$ according to the equation of $E_{\mathrm{pa}}(\mathrm{V})=$ $0.033 \ln v+0.1575(\mathrm{r}=0.9950)$.

The variation of peak potential, $E_{\mathrm{pa}}(\mathrm{V})$, with $\mathrm{pH}$ is shown in figure $3 \mathrm{~b}$. Based on $E_{\mathrm{pa}}=-0.0663 \mathrm{pH}+$ 0.6523 ( $\mathrm{r}=0.9999)$ and the Eq. (2), ${ }^{32}$ the number of $\mathrm{H}^{+}$taking part in the electrode reaction is calculated to be $m=2.24 \approx 2$.

$$
E_{\mathrm{pa}}=E^{0}-2.303(m R T / n F) \log H^{+},
$$

where $E^{0}$ is the formal potential, $\mathrm{m}$ is number of the protons involved in the reaction and $n$ is 2 (see above). Other terms have their usual significance. In the same ways, for NE, the plot of $E_{\mathrm{pa}}(\mathrm{V}) v s . \mathrm{pH}$ is $E_{\mathrm{pa}}=-0.069$ $p H+0.655(\mathrm{r}=0.9970)$, the sum of $\mathrm{H}^{+}$take part in the oxidation of $\mathrm{NE}$ is calculated to be $2.38 \approx 2$.

Consideration of above results and the literatures of, ${ }^{23,33}$ the redox mechanism of DA and NE on the PL-Asp/GCE could be deduced as Eqs. (1) and (2), respectively.

\subsection{Analytical application}

3.5a Linear regression equation, linear range and detection limit: Under the optimal conditions, using the anodic peak currents as the detection signals, the calibration curve for DA is obtained. The linear regression equations are $i_{\mathrm{pa}}=0.3304+1.0827 \times 10^{-4} \mathrm{C}_{D A}$ $(\mathrm{r}=0.9972)$ in the range of $1.06 \times 10^{-4} \sim 1.325 \times$ $10^{-5} \mathrm{~mol} \mathrm{~L}^{-1}$ (figure $6 \mathrm{a}$ ) and $i_{\mathrm{pa}}=4.2997+8.098 \times$ $10^{-6} \mathrm{C}_{D A}(\mathrm{r}=0.9985)$ in the range of $1.325 \times 10^{-5}$ $\sim 1.18 \times 10^{-8} \mathrm{~mol} \mathrm{~L}^{-1}$ (figure $6 \mathrm{~b}$ ), respectively. The detection limit is $1.0 \times 10^{-9} \mathrm{~mol} \mathrm{~L}^{-1}(\mathrm{~S} / \mathrm{N}=3)$. The linear calibration curves are separated into two sections may be related to the different modes of the electrode reaction in different concentrations of DA.

For NE, the linear regression equations are $i_{\mathrm{pa}}=$ $5.894 \times 10^{-6} C_{\mathrm{NE}}+7.9512 \times 10^{-5}(\mathrm{r}=0.9950)$ in the range of $1.01 \times 10^{-4} \sim 1.63 \times 10^{-5} \mathrm{~mol} \mathrm{~L}{ }^{-1}$ and $i_{\mathrm{pa}}=$ $4.1448 \times 10^{-5} C_{\mathrm{NE}}+1.285 \times 10^{-6}(\mathrm{r}=0.9990)$ in the range of $1.63 \times 10^{-5} \sim 3.15 \times 10^{-8} \mathrm{~mol} \mathrm{~L}^{-1}$, respectively. The detection limit is $4.31 \times 10^{-9} \mathrm{~mol} \mathrm{~L}^{-1}(\mathrm{~S} / \mathrm{N}=3)$.

The comparison of the proposed method with other electrochemical methods for determination of DA and NE is listed in table 1 . The results indicate that the sensor for detection of DA and NE have high sensitivity and wide linear range.
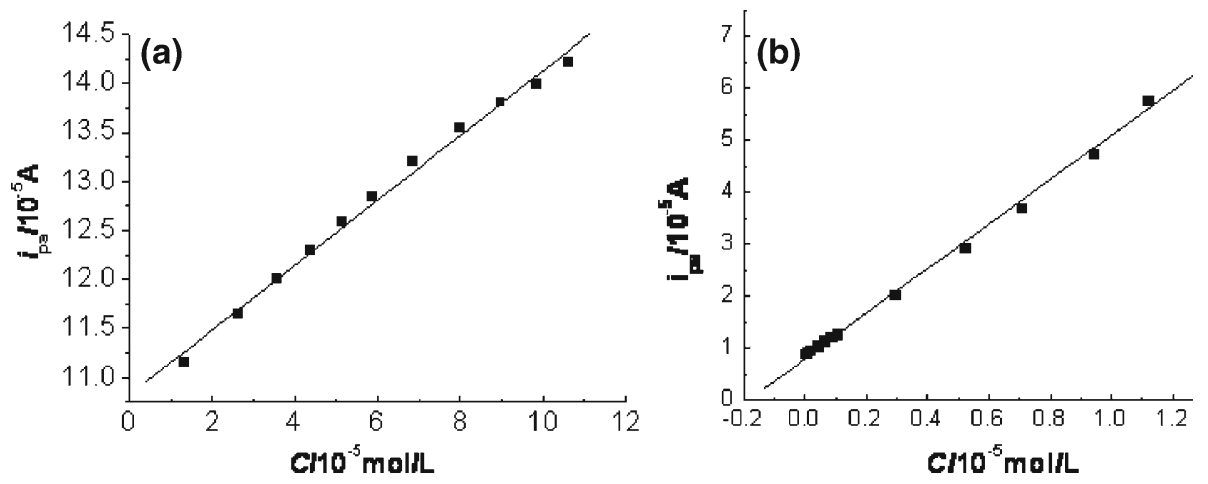

Figure 6. Plots of oxidation peak currents of DAvs. its concentrations (a: $1.06 \times$ $10^{-4}-1.325 \times 10^{-5} \mathrm{~mol} \mathrm{~L}^{-1}$; b: $1.325 \times 10^{-5}-1.18 \times 10^{-8} \mathrm{~mol} \mathrm{~L}^{-1}$ ) on the PLAsp/GCE. 
Table 1. Comparison of the proposed method with other electrochemical methods for determination of DA and NE.

\begin{tabular}{|c|c|c|c|c|}
\hline Analytes & Modified materials & Linear range $\left(\mathrm{mol} \mathrm{L}^{-1}\right)$ & Detection limit $\left(\mathrm{mol} \mathrm{L}^{-1}\right)$ & References \\
\hline \multirow[t]{12}{*}{ DA } & $\begin{array}{l}\text { carbon nanotubes-ionic } \\
\text { liquid composite }\end{array}$ & $2.0 \times 10^{-8}-7.0 \times 10^{-6}$ & $8.0 \times 10^{-9}$ & 9 \\
\hline & cysteine & $1.0 \times 10^{-6}-1.5 \times 10^{-4}$ & $1.8 \times 10^{-6}$ & 11 \\
\hline & carbon nanotubes & $1.0 \times 10^{-7}-8.0 \times 10^{-5}$ & $2.0 \times 10^{-9}$ & 12 \\
\hline & $\begin{array}{l}\text { Nafion/carbon-coated iron } \\
\text { nanoparticles-chitosan } \\
\text { composite membrane }\end{array}$ & $2.0 \times 10^{-6}-6 \times 10^{-4}$ & $8.3 \times 10^{-7}$ & 13 \\
\hline & 5-hydroxytryptophan & $5.0 \times 10^{-6}-3.5 \times 10^{-4}$ & $3.1 \times 10^{-7}$ & 14 \\
\hline & $\mathrm{LaFeO}_{3}$ nanoparticles & $1.5 \times 10^{-7}-8.0 \times 10^{-4}$ & $3.0 \times 10^{-8}$ & 15 \\
\hline & $\begin{array}{l}\text { Ferrocenyl-tethered } \\
\text { PAMAM dendrimers }\end{array}$ & $1.0 \times 10^{-5}-1.5 \times 10^{-3}$ & $4.7 \times 10^{-6}$ & 33 \\
\hline & gold nanoparticle & $0.2 \times 10^{-3}-1.2 \times 10^{-3}$ & $9.0 \times 10^{-5}$ & 34 \\
\hline & graphene & $4.0 \times 10^{-6}-1.0 \times 10^{-4}$ & $2.64 \times 10^{-6}$ & 35 \\
\hline & single-walled carbon nanotube & $9.9 \times 10^{-7}-3.0 \times 10^{-4}$ & $4.2 \times 10^{-7}$ & 36 \\
\hline & $\begin{array}{l}\text { multi-wall carbon } \\
\text { nanotube-poly(3,5-dihydroxy } \\
\text { benzoic acid) film }\end{array}$ & $1.0 \times 10^{-7}-7.0 \times 10^{-5}$ & $1.0 \times 10^{-8}$ & 37 \\
\hline & Poly(L-aspartic acid) & $\begin{array}{c}1.1 \times 10^{-4}-1.3 \times 10^{-5} \text { and } \\
1.3 \times 10^{-5}-1.2 \times 10^{-8}\end{array}$ & $1.0 \times 10^{-9}$ & This work \\
\hline \multirow[t]{4}{*}{$\mathrm{NE}$} & $\begin{array}{l}\text { carbon-coated nickel } \\
\text { magnetic nanoparticles }\end{array}$ & $12.0 \times 10^{-7}-8.0 \times 10^{-5}$ & $6.0 \times 10^{-8}$ & 23 \\
\hline & $\begin{array}{l}\text { polyacrylic acid-coated } \\
\text { multi-wall carbon nanotubes }\end{array}$ & $0-1.0 \times 10^{-5}$ & $1.31 \times 10^{-7}$ & 24 \\
\hline & $\begin{array}{l}\text { 2,2'-1,2 buthanediyl bis } \\
\text { (nitriloethylidyne).-bis- } \\
\text { hydroquinone }(\mathrm{BH}) \text { and } \\
\mathrm{TiO}_{2} \text { nanoparticles }\end{array}$ & $4.0 \times 10^{-6}-1.1 \times 10^{-3}$ & $0.5 \times 10^{-6}$ & 25 \\
\hline & Poly(L-aspartic acid) & $\begin{array}{c}1.01 \times 10^{-4}-1.63 \times 10^{-5} \text { and } \\
1.63 \times 10^{-5}-3.15 \times 10^{-8}\end{array}$ & $4.31 \times 10^{-9}$ & This work \\
\hline
\end{tabular}

3.5b Reproducibility and stability of L-Asp/GCE: The reproducibility and stability of the biosensor is investigated by cyclic voltammetry on the modified electrode. The peak parameters of $1.05 \times 10^{-5} \mathrm{~mol} \mathrm{~L}^{-1}$ DA detected a time every 10 days in 30 days are listed in table S2 (supporting information). The parameters have not obviously changed, showing that the biosensor has long-term stability. After a time of determination is finished, the poly(L-Asp) can be removed from the electrode surface by cyclic scanning from $0.0 \mathrm{~V}$ to $0.6 \mathrm{~V}$ at the scan rate of $100 \mathrm{mV} \mathrm{s}^{-1}$ in PBS solution (pH 5.0) until no redox peaks appear, then the electrode can be coated with poly(L-Asp) again. After this course is repeated for 8 times, the detection signal is about $97 \%$ of the first measurement signal. The results show that the biosensor has good reproducibility. To ascertain electrode-to-electrode reproducibility, the parameters are also recorded on a batch of 6 modified electrodes prepared independently and the results are listed in table S3 (supporting information), which indicate that the reproducibility of electrode-to-electrode is very good. 3.5c Tolerance of foreign substances: The influences of 300 times concentration of UA and AA on the determination of $1.05 \times 10^{-5} \mathrm{~mol} \mathrm{~L}^{-1} \mathrm{DA}$ are investigated by cyclic voltammetry and the results are shown in figure 7. DA had a couple of redox peak currents (Peaks b and b') in the presence of UA (Peak a) and AA (Peak c) on the PL-Asp/GCE. UA and AA have only an anodic peak, respectively. The difference of the anodic peak potential between DA and UA, DA and $\mathrm{AA}$, are $157 \mathrm{mV}$ and $191 \mathrm{mV}$, respectively. So we can say confidently that UA and AA have no influence on the determination of DA.

The influences of 300 times concentration of UA and AA on the determination of $1.58 \times 10^{-5} \mathrm{~mol} \mathrm{~L}^{-1} \mathrm{NE}$ are also studied, the anodic peak potential separation between NE and UA, NE and AA, are $276 \mathrm{mV}$ and $243 \mathrm{mV}$. Therefore, UA and AA have no interference for the determination of NE, too.

Under the optimal conditions, the interference of many foreign substances, such as metallic ions, anions and amino acids, on the determination of $1.05 \times$ $10^{-5} \mathrm{~mol} \mathrm{~L}^{-1} \mathrm{DA}$ and $1.58 \times 10^{-5} \mathrm{~mol} \mathrm{~L}^{-1} \mathrm{NE}$ is also 


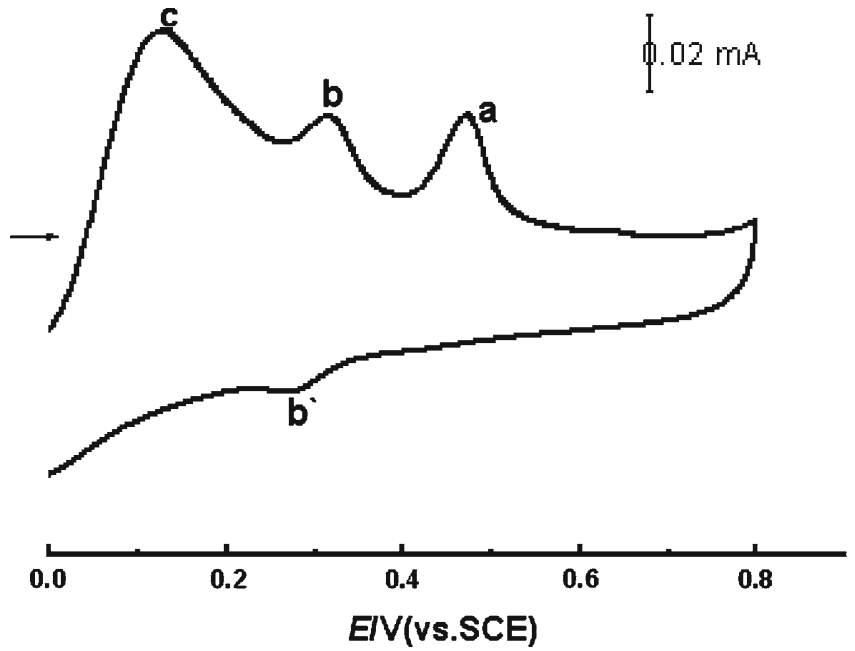

Figure 7. Cyclic voltammograms of $1.05 \times 10^{-5} \mathrm{~mol} \mathrm{~L}^{-1}$ DA on the PL-Asp/GCE in pH 5.0 PBS solution containing 300 times concentration of AA and UA.

investigated. The results are as follows: for determination of DA or NE, if the $\pm 5 \%$ error is allowed, 200 times of some amino acids, such as D, L-aspartic acid, D-threonine, L-serine, etc., 240 times of citric acid and tartaric acid; 120 times of ions, such as $\mathrm{K}^{+}, \mathrm{Na}^{+}, \mathrm{Fe}^{3+}$, $\mathrm{Fe}^{2+}, \mathrm{Cu}^{2+}, \mathrm{Mg}^{2+}, \mathrm{Cl}^{-}$, had no obvious influence.

3.5d Recovery test: The practical application of the PL-Asp modified electrode is tested by measuring the concentration of DA and NE in injections which are produced in different batches. The standard addition technique is used for recovery tests. The amounts of DA and NE in injections are calculated from the calibration equation and the results are listed in table S4 (supporting information).

\section{Conclusion}

In this paper, an easy method for preparation of poly (L-aspartic acid) membrane on the GCE surface is described. The membrane exhibited good properties, in electrochemical response of DA and NE, such as fast response time (less than $2 \mathrm{~s}$ ) and broad linear range, and in eliminating the interference of AA and UA. Based on this, a method for determination of DA and NE was setup. This method has been applied to analyse the concentration of DA and NE in injections with satisfactory results. The results show that this method is a simple and practical method with good selectivity for quantitative detection of DA and NE. The biosensor can be prepared and regenerated by a simple procedure with good reproducibility and long-term stability.

\section{Supplementary information}

Tables S1-S4 are given as supplementary material. (see www.ias.ac.in/chemsci).

\section{Acknowledgements}

This work was supported by the Natural Science Foundation Committee of Shandong Province, China (No. ZR2009BM003), the National Natural Science Foundation of China (21105023) China Postdoctoral Science Foundation Funded Project (No. 200902558; No. 20080430193), and Shandong Province Postdoctoral Innovation Foundation Funded Project, China (No. 200702020).

\section{References}

1. Gotoh M, Takagi J, Mori S, Yatoh M, Hirooka Y, Yamanouchi K and Smythe G A 2001 Brain Res. 919 155

2. Kvetnansky R, Noskov V B, Blazicek P, Macho L, Grigoriev A I, Goldstein D S and Kopin I J 1994 Acta Astronaut. 34243

3. Hows M E P, Lacroix L, Heidbreder C, Organ A J and Shah A J 2004 J. Neurosci. Methods 138123

4. Jung M C, Shi G Y, Borland L, Michael A C and Weber S G 2006 Anal. Chem. 781755

5. Zhu M, Huang X M, Li J and Shen H X 1997 Anal. Chim. Acta 357261

6. Whiting M J 2009 Ann. Clin. Biochem. 46129

7. Lu L P, Wang S Q and Lin X Q 2004 Anal. Chim. Acta 519161

8. Wu H P, Cheng T L and Tseng W L 2007 Langmuir 23 7880

9. Sun Y, Fei J, Hou J, Zhang Q, Liu Y and Hu B 2009 Microchim. Acta 165373

10. Ates M, Castillo J, Sezai Sarac A and Schuhmann W 2008 Microchim. Acta 160247

11. Zhang L 2008 Microchim. Acta 161191

12. Qing W, Liu X, Lu H, Liang J and Liu K 2008 Microchim. Acta 160227

13. Lai G, Zhang H and Han D 2008 Microchim. Acta 160 233

14. Li Y, Huang X, Chen Y, Wang L and Lin X 2008 Microchim. Acta 164107

15. Wang G, Sun J, Zhang W, Jiao S and Fang B 2008 Microchim. Acta 164357

16. Chen P Y, Vittal R, Nien P C and Ho K C 2009 Biosens. Bioelectron. 243504

17. Prakash S, Rao C R K and Vijayan M 2009 Electrochim. Acta 545919

18. Wang Y, Li Y M, Tang L H, Lu J and Li J H 2009 Electrochem. Commun. 11889

19. Thiagarajan S, Tsai T H and Chen S M 2009 Biosens. Bioelectron. 242712

20. Wei M, Terashima C, Fujishima M L A and Gu Z Z 2009 Chem. Commun. 3624 
21. Arguello J, Leidens V L, Magosso H A, Ramos R R and Gushikem Y 2008 Electrochim. Acta 54560

22. Abbaspour A and Ghaffarinejad A 2009 Anal. Chem. 81 3660

23. Bian C, Zeng Q, Xiong H, Zhang X and Wang S 2010 Bioelectrochem. 791

24. Huang S, Liao H and Chen D 2010 Biosens. Bioelectron. 252351

25. Mohammad M, Hadi B, Mohammad A S, Hossein N and Nima T 2010 Appl. Catalys. A 378195

26. Zhang L and Lin X 2005 Anal. Bioanal. Chem. 382 1669

27. Ma W and Sun D M 2007 Acta Phys. Chim. Sin. 23332

28. Jiang C, Yang T, Jiao K and Gao H 2008 Electrochim. Acta 532917

29. Wang X L, Yang T, Feng Y Y, Jiao K and Li G C 2009 Electroanalysis 21819
30. Laviron E 1979 J. Electroanal. Chem. 10119

31. Bard A J and Faulkner L R 2001 Electrochemical methods: Fundamentals and applications (New York: John Wiley and Sons Inc), pp. 97

32. Bond A M 1980 Modern polarographic methods in analytical chemistry (New York: Marcel Dekker), pp. 27

33. Chen Q, Ai H, Ma Q and Yin H 2010 J. Appl. Electrochem. 401379

34. Jahan B R, Abolfazl K, Reza O, Roudabeh V and Sahar R 2010 J. Solid State Electrochem. 141171

35. Kim Y, Bong S, Kang Y, Yang Y, Mahajan R K, Kim J S and Kim H 2010 Biosen. Bioelectron. 252366

36. Cao X, Zhang L, Cai W and Li Y 2010 Electrochem. Commun. 12540

37. Zhou X, Zheng N, Hou S, Li X and Yuan Z 2010 J. Electroanal. Chem. $\mathbf{6 4 2} 30$ 